\title{
A educação ambiental na sociedade contemporânea: bricolagem pedagógica ou projeto antropológico? ${ }^{1}$
}

\section{Introdução}

Bernard Charlot ${ }^{2}$

Eu não sou especialista em educação ambiental, mas, nos últimos anos, trabalhei sobre a questão antropológica em educação e encontrei temas que me parecem importantes quando há interesse pela educação ambiental: o que é um ser humano, quais são o seu passado e seu futuro, quais são e quais devem ser suas relações com o mundo?

Essas questões são fundamentais para pensar um projeto de educação ambiental. Mas, será que hoje em dia existe um projeto de educação ambiental? Um projeto antropologicamente fundado sobre uma definição da espécie humana e das suas relações com um mundo? Um projeto discutido em um amplo debate público? Não conheço um projeto desse tipo. Quando se trata de educação ambiental, a questão antropológica apenas aflora, sem ser aprofundada de forma explícita, apesar de que, a meu ver, a educação ambiental não deve silenciar a questão do ser humano, do seu mundo, do seu futuro, ou seja, a questão antropológica.

O que eu vejo? Eu vejo, nas salas de aula, a questão ambiental como um desejo, uma esperança, uma forma de denunciar o que está acontecendo. Eu vejo a questão ambiental como um complemento das aulas de Biologia, de Geografia, às vezes de História ou de Arte. Eu vejo a questão ambiental focando conselhos práticos, sobretudo a respeito da poluição e do que não se deve fazer. Eu não encontro um discurso ambicioso da educação ambiental sobre o ser humano e seu futuro. Até que, muitas vezes, o discurso ecológico desvaloriza a espécie humana, reduzindo o homem a um macaco desastroso.

Sendo assim, muitas vezes, de fato, a educação ambiental é um conjunto de bricolagens. São bricolagens simpáticas, e isso é melhor do que nada, mas são um tanto irrisórias quando se pensa no que está em jogo: o futuro da espécie humana e do seu mundo, bem como a necessidade de mudanças radicais em nossos padrões de vida. Além disso, alguns programas oficiais de educação ambiental funcionam como álibis para não mudar coisa importante.

É essa questão que gostaria de levantar, hoje: a educação ambiental, na sociedade contemporânea, é uma bricolagem pedagógica ou um projeto antropológico? Minha resposta: é uma bricolagem pedagógica. Portanto, convido-os a refletir, neste encontro, sobre como tornar a educação ambiental um projeto antropológico, para além da bricolagem cotidiana.

Não estou criticando a educação ambiental em particular. Na verdade, a questão é mais geral: hoje em dia, não existe uma pedagogia contemporânea (por mais paradoxal que possa parecer essa afirmação). Conhecemos uma pedagogia chamada tradicional; conhecemos algumas pedagogias novas, mas não temos uma pedagogia contemporânea. Evidentemente, sempre podemos chamar de contemporâneos, por definição, os discursos atuais sobre a educação, mas o que quero afirmar é que não temos uma pedagogia que aborde como questão central a formação do ser humano enquanto ser humano.

\footnotetext{
${ }^{1} \mathrm{O}$ presente texto é fruto da transcrição para a forma escrita da conferência de abertura ministrada pelo professor Bernard Charlot durante o X EPEA, que teve como tema Perspectivas da Educação Ambiental no cenário brasileiro atual. A transcrição foi realizada pela professora Mônica Andrade Modesto e pelo aluno Raul Soares Bonfim, ambos do curso de Pedagogia da Universidade Federal de Sergipe. A versão final do texto foi estabelecida por Bernard Charlot.

${ }^{2}$ Possui doutorado em Educação (doctorat d État, equivalente a Livre-docência) - Université de Paris X, Nanterre (1985). Atualmente, é Professor-Visitante na Universidade Federal de Sergipe, onde é membro do curso de PósGraduação em Educação (PPGED). É, também, Professor Titular Emérito da Universidade Paris 8. Na UFS, é membro do Grupo de pesquisa CNPq Educação e Contemporaneidade (EDUCON).
} 
Aliás, não há mais, em nossa sociedade, grandes debates sobre a Educação. Nas décadas de 1970 e 1980, nas livrarias, a Educação ainda tinha um lugar de destaque. Esse lugar quase não existe mais. Quem quiser ver um livro sobre Educação tem que procurar nas prateleiras dedicadas à Psicologia, à Sociologia, até mesmo à Autoajuda. Encontram-se cada vez mais textos de autores que se acham especialistas em Pedagogia, sendo que, na verdade, vendem autoajuda.

Portanto, o silêncio antropológico da educação ambiental é um caso particular de uma questão mais geral. Mas esse silêncio da educação ambiental é preocupante porque ela trata de questões fundamentais em nosso mundo. Acho que a questão antropológica poderia ser o centro de gravidade de um projeto de educação ambiental, sobretudo por essa educação ainda estar mal definida e não poder se apoiar sobre um conjunto de textos e práticas antigas, como o fazem a Matemática ou a História.

Não existe uma pedagogia contemporânea: por quê? Esse será o foco da primeira parte da minha palestra. A seguir, questionarei: como reintroduzir a questão do ser humano e de suas relações com o mundo no coração da reflexão sobre a educação, inclusive a educação ambiental? Não focarei o comportamento individual da criança ou a criança pensada como um cidadão, como a escola já faz, mas a criança como membro da espécie humana. O que leva a uma questão difícil, árida, quando se procura uma resposta científica: o que é o ser humano?

\section{$2 O$ silêncio antropológico do discurso contemporâneo sobre a educação}

Como já disse, não existe uma pedagogia contemporânea. Isso não quer dizer que não se fala mais de educação. Até que, às vezes, fala-se muito dela. Falamos da qualidade da educação, falamos de neuroeducação, falamos de tecnologias digitais na educação, falamos de cibercultura, falamos de tudo, menos da questão antropológica, da criança enquanto membro da espécie humana. Desse ponto de vista, podemos dizer que o silêncio pedagógico da sociedade contemporânea é um silêncio barulhento.

Para melhor entender essa situação, eu fui ver como funcionava, basicamente, o discurso da pedagogia clássica, quer seja nas suas formas tradicionais, quer seja nas formas chamadas de novas.

Há várias formas de pedagogia tradicional, umas mais filosóficas, mais religiosas, outras mais republicanas. Mas, sempre a questão central é aquela do encontro entre o desejo e a norma. Ora, isso nos interessa do ponto de vista da educação ambiental porque a relação entre o desejo e a norma é, também, uma questão fundamental da educação ambiental.

A pedagogia tradicional tida como religiosa explica que a criança tem uma natureza corrupta. Essa ideia é estranha para nós, que pensamos a criança como inocente, espontânea etc., mas a história representa a criança como um ser que tem uma natureza selvagem. $\mathrm{Na}$ interpretação religiosa, essa natureza é corrupta. É normal, porque a criança nasce do ato sexual, considerado como um pecado original pela interpretação da Igreja - não tenho certeza de que isso seja na Bíblia, mas não vou abrir, aqui, um debate teológico. A criança nasce do pecado, portanto é corrupta. Prova de que ela tem uma natureza corrupta: é só deixar uma criança cinco minutos sem ser vigiada que ela vai fazer uma bobagem. Há pouco tempo, porém, que ela nasceu e, portanto, há pouco tempo que ela vive na corrupção. Além do mais, Jesus disse: Deixa vir a mim as criancinhas! Portanto, a criança, ao mesmo tempo em que é o ser mais corrupto que possa existir, é também o mais fácil de tirar fora da corrupção, graças à educação. Não estou inventando nada. Os textos dizem isso de forma muito clara! Por exemplo, os padres de Port-Royal dizem que a criança é como se fosse uma fortaleza assediada pelo diabo e que não se defende. São páginas e páginas desses discursos, que construíram as nossas práticas pedagógicas: a educação é uma luta contra a natureza da criança, portanto, contra seus desejos, e, obviamente, contra seu corpo, fonte dos desejos (CHARLOT, 2013, 2020). 
A forma republicana da pedagogia tradicional muda o discurso, as referências, mas não muda as práticas, porque é o mesmo projeto fundamental: a educação como luta contra a natureza. Só que a natureza não é mais descrita como pecado, mas como emoção, paixão, ou seja, novamente, como desejo: a educação deve desenvolver a razão contra a emoção, contra as paixões. E, de novo, a pedagogia republicana, como a dos Jesuítas, vai ser uma pedagogia da disciplina, da norma. Como dizia Kant, não se enviam as crianças à escola apenas para que elas adquiram conhecimentos, mas para que, em primeiro lugar, elas aprendam a ficar sentadas sem se mexer. Porque não tem desenvolvimento da razão sem disciplina do corpo. Estamos repetindo as mesmas práticas em nossas escolas. O primeiro trabalho de um professor é disciplinar a natureza, que é algo perigoso. Entretanto, a análise mostra que essas pedagogias tradicionais só podem funcionar quando conseguem fazer com que a própria norma seja desejável - como salvação da alma ou acesso à dignidade de cidadão e ao progresso (CHARLOT, 2020).

A pedagogia nova inverte os dados do problema, mas o problema permanece: a relação entre o desejo, chamado de natureza, e a norma. Na pedagogia nova, a natureza não é o inimigo a ser combatido; bem pelo contrário, ela deve nortear a educação, pois educar uma criança é acompanhá-la no seu desenvolvimento natural - esse desenvolvimento que Piaget tenta esclarecer na sua Psicologia genética. Nessa perspectiva, deve-se respeitar o desenvolvimento natural da criança; ela é espontânea, não é corrupta, mas pura, autêntica e, se o adulto pudesse permanecer criança, não haveria problemas no mundo. Portanto, a educação deve preservar a natureza da criança contra a norma adulta, que é uma forma de petrificação. Mas, dessa vez, a análise mostra que essas pedagogias novas só podem funcionar quando conseguem reintroduzir no processo educativo normas consideradas legítimas - legítimas por serem impostas pela própria natureza, ou pela coletividade em funcionamento democrático, ou pelo próprio projeto da criança.

Assim, historicamente, a questão pedagógica central é a questão da relação entre o desejo e a norma. As pedagogias da Norma precisam da desejabilidade da norma, e as pedagogias do Desejo precisam de normas legítimas. No coração da pedagogia, encontra-se a dialética do Desejo e da Norma.

Penso que essa seja uma questão fundamental do ponto de vista da educação ambiental. Vivemos numa sociedade do consumo, em que proliferam cada vez mais desejos, criados, incentivados pela lógica de lucro dessa sociedade e não temos recursos que possibilitem satisfazer todos os desejos. Portanto, precisamos de normas, inclusive para salvar o planeta e a própria espécie humana. Mas, quais normas? Como definir essas normas? Quais normas podem ser consideradas como legítimas para controlar, para disciplinar o desejo? Essa é uma grande dificuldade!

Não encontrei uma resposta pedagógica disponível na educação ambiental. Bem pelo contrário, geralmente a educação ambiental é contra a normatização e, portanto, de fato, do lado do desejo contra a norma. O problema é que é o desejo que leva ao consumo sem freio, não apenas de todos os recursos, mas do planeta mesmo. Geralmente, a resposta dos defensores da educação ambiental é: temos que voltar aos desejos naturais. Mas, gostaria que me explicassem quais são os desejos que podem ser considerados naturais em nossa sociedade, e como vamos fazer com aqueles que pretendem satisfazer outros tipos de desejos, se recusarmos a ideia de norma. Defendo a ideia de que precisamos de uma pedagogia que fundamente a legitimidade dos desejos e das normas numa representação aceita da espécie humana, da sua história e do seu destino.

Qual é a situação hoje? Socialmente, o desejo é considerado legítimo; economicamente, ele é tratado como necessário, mas, ao mesmo tempo, na vida cotidiana, temos que frear os desejos de nossos filhos ou alunos e, sendo assim, negociamos, fazemos bricolagens, sem termos uma pedagogia contemporânea que providencie referências fundamentais para nós. 
Não podemos mais nos apoiar sobre uma teoria fundadora ou encontrar respostas em grandes debates pedagógicos. Decerto, ainda existem pais e professores que são mais tradicionais, rígidos, às vezes reacionários, e outros que são mais abertos. Todavia, raramente a base deles é uma referência filosófica, antropológica, trata-se mais de uma relação com a vida. Como gerimos tal situação? Um pouco disso, um pouco daquilo...

$\mathrm{O}$ que fazem os professores? Eles têm uma pedagogia basicamente tradicional, porque a escola é organizada para uma pedagogia tradicional, mas eles tentam abrir parênteses do tipo construtivista: inserem um pouco de pesquisa, um pouco de internet, um pouco de trabalho em grupo etc. E os pais, o que fazem? Uma pedagogia mais aberta que outrora, mas eles têm que impor limites, não podem prescindir dos limites. Na verdade, pais e professores fazem bricolagens para tentar resolver os problemas cotidianos, desenvolvem práticas híbridas, mistas, instáveis, não estruturadas por referências teóricas.

O que queremos para nossos filhos? Quaisquer que sejam nossos discursos, queremos, em primeiro lugar, que eles tenham um bom emprego mais tarde. Podemos ser mais abertos ou mais tradicionais, podemos ser revolucionários, mas, de fato, queremos que os nossos filhos tenham um bom futuro, pensado como um bom emprego mais tarde. Do que falam os jornalistas e os políticos quando falam da educação? Do mercado, do bom emprego, da formação profissional, do trabalho. Não da felicidade, do valor do ser humano ou da grandeza da espécie humana.

A lógica da sociedade contemporânea é uma lógica da concorrência, do desempenho, do mercado e, nessa lógica, cada um de nós vale o seu próprio peso nesse mercado. Estamos vivendo em uma sociedade na qual nossos filhos e nossos alunos vão ter que concorrer em vários mercados, econômico, cultural, do esporte, da arte, da beleza etc. Nessa lógica de concorrência, não é possível construir uma pedagogia contemporânea, fundamentada em referências antropológicas. O único discurso antropológico que essa lógica pode propor é aquele que desenvolveu Adam Smith e que dissemina o liberalismo: cada um por si, perseguindo seu próprio interesse. Nesse discurso, a única coisa que os seres humanos têm em comum é o egoísmo e a concorrência, ou seja, as fontes de um confronto permanente e cotidiano - esse confronto, essa correria louca para o nada, que leva aos desastres humanitários e ecológicos contemporâneos.

Não estou falando apenas de grandes assuntos filosóficos e políticos, mas, também, das práticas. Por que nossos alunos estudam (quando estudam...)? Para quê? Por causa da prova, para ter uma boa nota, para não ficar reprovados. Quantos alunos estudariam se tivessem a certeza de que, mesmo sem estudar, eles iriam passar de ano?

$\mathrm{Na}$ França, houve o movimento dos chamados coletes amarelos, que nasceu para recusar uma taxa automobilística no momento em que o carro era, em muitos lugares, o único meio de transporte. Não são pessoas sem consciência ecológica, mas elas dizem: vocês me falam do fim do mundo, eu falo do fim do mês. Na educação ambiental, falamos aos nossos alunos do fim do mundo, e eles estão preocupados com o fim do semestre para não cair na reprovação e não ter que repetir o ano.

Não se pode pensar uma educação ambiental que trate das questões fundamentais, a da espécie humana, a do futuro do mundo, se a escola continuar funcionando como um lugar de concorrência, de avaliação permanente, de ameaça de reprovação, sendo tudo isso mais importante que a formação. Nesse tipo de escola, é uma brincadeira pretender dar uma educação ambiental; é uma contradição falar de educação ambiental em um lugar dominado pela competição, quando as lógicas de concorrência sustentam formas econômicas e sociais que derrubam, aos poucos, nosso mundo.

Temos que entender que não haverá um progresso ambiental se não mudarmos profundamente, radicalmente, as lógicas sociais dominantes de desempenho e concorrência. Sem essas mudanças, sem referências antropológicas fundamentais, a educação ambiental será 
mais uma matéria escolar: vou fazer uma aula de educação ambiental e prestem bem atenção, porque vai ter uma nota e quem não atingir a média vai ficar de recuperação em educação ambiental...

Nessa sociedade contemporânea do desempenho e da concorrência, o que aconteceu com a dialética do desejo e da norma? Hoje em dia, o desejo é legítimo e a norma é decidida pelo mercado.

A sociedade tradicional, durante séculos e séculos, foi uma sociedade da poupança. A pedagogia dessa sociedade era a pedagogia tradicional: a poupança é uma forma de se preparar para enfrentar um futuro que exige que se resista ao desejo imediato. Quando eu era menino, na escola primária, na década de 1950 em Paris, o professor recebia nosso pouco de dinheiro para colocar no que seria, aqui, a poupança da Caixa Econômica Federal. Não era para ganhar os juros, era um processo pedagógico, para que a criança aprendesse a não gastar o seu dinheiro e, portanto, a desistir do desejo.

A pedagogia tradicional é uma pedagogia antidesejo e, portanto, uma pedagogia da poupança. A nossa sociedade não é uma sociedade da poupança, é uma sociedade do crédito e da publicidade. A poupança exige que você não consuma, apesar de ter o dinheiro para fazê-lo. $\mathrm{O}$ crédito permite consumir de imediato, sem precisar ter dinheiro. E a publicidade multiplica, sempre mais, os desejos. Estamos vivendo em uma sociedade que legitima e incita o desejo. Não é uma questão apenas ética, mas, em primeiro lugar, uma questão econômica: a partir do momento em que entramos em uma sociedade que visa o desenvolvimento, na década de 1960, essa sociedade precisou muito do consumo - e o consumo precisa do desejo.

Uma pedagogia tradicional, da poupança, desvalorizando o desejo, não combina com uma sociedade que precisa do consumo para sobreviver. Sobretudo que, ao mesmo tempo em que acontece a legitimação do desejo, nascem novos sujeitos, novas formas de vida sexual, novas formas de convivência conjugal, que enfraquecem as normas mais antigas, como autoridade e hierarquia. Sendo assim, a nossa pedagogia tradicional só consegue sobreviver ameaçando, permanentemente, o aluno: nota ruim, reprovação, repetência - e quando os alunos nem sequer se preocupam com a nota, porque desistiram até dela, o professor fica sem recurso.

As pedagogias tradicionais perderam as suas forças, mas não se implantaram pedagogias novas, a não ser em algumas ilhas pedagógicas. Com efeito, não se podem desenvolver pedagogias novas em uma sociedade da concorrência, porque a pedagogia nova, por definição, não funciona em uma lógica de concorrência. Portanto, ficamos sem nenhum fundamento pedagógico sólido e coerente. Mas, apesar de tudo, jovens continuam a nascer e crescer e temos de educá-los. Para tanto, desenvolvemos bricolagens de sobrevivência. A dialética do desejo e da norma não é mais regulada por uma antropologia, ela foi abandonada ao livre jogo do mercado, mas temos filhos, temos alunos e devemos, de uma forma ou outra, regular o encontro de desejos conflituosos e ajudar sujeitos a se estruturarem. O que não é possível, como mostra muito bem a psicanálise, sem normas e limites. Entretanto, ainda que não exista mais um discurso antropologicamente fundado, ainda se fala da educação. Não tenho tempo, aqui, para desenvolver a análise dos novos discursos sobre a educação, mas quero, pelo menos, apontar para eles (CHARLOT, 2019, 2020). Na verdade, não são mesmo discursos sobre a educação, mas sobre a otimização dos processos de memorização e aprendizagem na sociedade da concorrência.

Há o discurso sobre a qualidade da educação. Todo mundo está a favor da qualidade da educação, mas esse discurso nunca define quais são os critérios dessa qualidade. O que não é de se admirar, uma vez que, na verdade, o objetivo não é qualitativo, é quantitativo: ter mais pontos no ENEM, melhor IDEB, melhor lugar na avaliação PISA (que compara jovens de quinze anos) ou no ranking de Shangai (que classifica as universidades).

Há o discurso da neuroeducação, que se aproveita das pesquisas em neurociências (legítimas e, às vezes, interessantes para melhor entendermos os processos de memorização e 
aprendizagem) para tentar nos vender opiniões que, na verdade, raramente são fundadas nas pesquisas científicas e que, quase sempre, ignoram as profundas diferenças entre laboratório científico e sala de aula.

Há discursos sobre tecnologias digitais que podem ser interessantes do ponto de vista técnico, mas que, em si, não resolvem a questão mais ampla do desejo de aprender e da relação com o saber e, portanto, deixam aberta a questão pedagógica. A forma atual mais frequente do uso de Internet pelos alunos (e, às vezes, pelos professores...) é o copiar-colar, não é uma manifestação de alguma cibercultura... Aliás, essa ideia interessante de cibercultura desembocou nas fake news, nos tweets de Donald Trump, no Gabinete do ódio do Planalto, no cyberbullying, no assédio e nas múltiplas formas da tecnobarbárie contemporânea.

Esses discursos valorizam a rede (neuronal ou informática), a conectividade, o desenvolvimento sem freio, uma forma de transhumanismo. O que uma educação ambiental pode fazer com discursos cujo horizonte é a concorrência em todas as esferas da vida? Minha aposta é que devemos opor a esses discursos uma antropo-pedagogia que faça, claramente, a escolha pelo ser humano.

\section{Para uma antropo-pedagogia contemporânea}

Eu defendo a ideia de reintroduzir a questão do ser humano no centro da reflexão pedagógica - não apenas da criança como sujeito e futuro cidadão, mas do ser humano enquanto espécie humana. Do ponto de vista científico, Sapiens é o resultado de uma longa e tempestuosa aventura, não planejada, improvável e que não poderia se repetir sob as mesmas formas. Alguns resultados da paleoantropologia merecem particular destaque.

Somos resultados de uma história em que existiram várias espécies humanas e não somente a nossa: habilis, rudolfensis, ergaster, erectus, heidelbergensis, neandertal, denisova e outras espécies do gênero Homo. Algumas dessas espécies coabitaram na Terra por dezenas de milhares de anos. Sapiens e Neandertal habitaram a Europa juntos entre 40000 e 28000 anos BP (before present), ou seja, por mais de dez mil anos. Destaco o verbete juntos, porque Sapiens e Neandertal existiam em pequenos grupos de umas cem pessoas, que não viviam no mesmo lugar e raramente se encontravam. No entanto, aconteceram encontros, com prováveis trocas culturais e até um pouco de miscigenação biológica - vocês e eu temos alguns genes herdados de Neandertal.

Isso significa que somos a última espécie viva de um gênero Homo que incluiu várias espécies - enquanto ainda existem dezenas de espécies de macacos. A maioria das espécies humanas desapareceram, depois de viverem dezenas e, às vezes, centenas, de milhares de anos. Somos os últimos humanos vivos, não por sermos melhores por natureza, mas por termos herdado de outras espécies, por termos conseguido inventar novas formas de sobrevivência coletiva - e, também, por uma boa dose de sorte ao longo de nossa história.

Aqui, abro um parêntese interessante; chamo a sua atenção para o fato de que a extinção das espécies é um processo normal na evolução. Mais de $90 \%$ das espécies que já existiram desapareceram, inclusive todas as espécies humanas fora de Sapiens. Do ponto de vista da evolução, o problema não é a extinção das espécies, o problema é que, no movimento normal da evolução, há uma dinâmica de espécies que desaparecem $e$ de outras que aparecem, que as substituem. O problema fundamental, atual, não é a extinção. Decerto, ela é maciça, importante, mas já aconteceram várias extinções maciças na história da evolução - inclusive aquela que, 65 milhões de anos atrás, acabou com os dinossauros, o que permitiu a expansão dos mamíferos. O problema atual é que, por causa do ser humano, o processo duplo de extinção $e$ criação não funciona mais.

Merece destaque, também, o fato de que o que foi considerado como o próprio do homem se encontra, sob formas mais simples, em outras espécies animais, em particular nos 
chimpanzés - com os quais temos um antepassado comum relativamente próximo, uma vez que a divergência entre as duas espécies aconteceu apenas sete milhões de anos atrás. O homem não é o único bípede, há outros; mas ele é o único que consegue se manter imóvel ou correr sobre duas pernas. Da mesma forma, outros animais usam ferramentas, embora o homem seja o único que emprega ferramentas para construir outras ferramentas.

No que diz respeito à linguagem, somos os únicos que falam, porque só os homens têm o equipamento biológico necessário para falar, mas não somos os únicos que têm um sistema de comunicação, embora o nosso seja particularmente sofisticado e eficaz. Resumindo: somos seres biológicos, como os demais seres vivos, mas temos especificidades bastante interessantes.

Fomos criados pelo movimento biológico da evolução, mas esse próprio movimento evolutivo fez com que, aos poucos, no tempo, nos tornássemos diferentes dos outros animais. Existe uma evolução contínua no movimento da vida, mas houve saltos qualitativos no decorrer dessa evolução. Aconteceu um salto qualitativo, há dois milhões de anos, com Homo Ergaster, a forma inicial, africana, de Homo Erectus. Aconteceu, provavelmente, outro salto qualitativo há quinhentos mil anos, com o antepassado comum de Neandertal e de Sapiens e um novo salto qualitativo com Sapiens entre setenta mil e quarenta mil anos. Essa é a nossa história. Somos como os outros, mas diferentes dos outros, não por natureza, não por essência, mas pela história da evolução.

Fomos construídos por uma evolução em mosaico, como dizem os cientistas - um duplo mosaico, biológico e cultural. Várias mudanças biológicas convergem de repente, produzindo um novo desenho, como um mosaico. Do mesmo modo, várias mudanças culturais concorrem para um novo mosaico. E quando os dois processos, biológico e cultural, juntam seus efeitos, pode se produzir um salto qualitativo (CHARLOT, 2020). Portanto, de certo ponto de vista, não somos importantes, somos seres biológicos como todos os demais, em um planeta que pode existir sem nós. Entretanto, apesar de tudo, apesar de sermos como os outros, somos diferentes e, pessoalmente (e sem pretender ser neutro, obviamente), acho essa diferença interessante, valiosa.

O resultado dessa aventura improvável que levou ao ser humano é uma dupla especificidade.

Somos específicos pelo nosso genoma. Esse é o caso de cada espécie, por definição, uma vez que, se seu genoma não fosse específico, ela não seria uma espécie diferente das outras. Mas o genoma da espécie humana é epigenético, como diz a Genética contemporânea: muitos genes são potencialmente disponíveis no momento do nascimento, mas só irão entrar mesmo em ação, se atualizar, se eles encontrarem um meio humano que exija essa atualização. Assim se explica essa grande plasticidade do ser humano, identificada já faz tempo como uma especificidade de nossa espécie. O ser humano nasce com um genoma que vai lhe possibilitar viver em várias formas de habitat, de nicho ecológico, de mundo, enquanto o chimpanzé, o nosso mais próximo primo, não pode viver em qualquer habitat.

Somos também específicos pelo nosso mundo. Até que, a meu ver, para entender o que é o próprio do homem, não é necessário entrar em discussões complicadas para saber se o chimpanzé usa ou não ferramenta, é só ver o nosso mundo. Nenhuma espécie construiu uma coisa nem um pouco semelhante a esse mundo. O mundo é humano, profundamente humano, ele é uma forma objetivada do humano, ele foi construído ao longo do tempo por várias espécies humanas, como uma sedimentação das energias, das tentativas, dos sucessos e também dos malfeitos, dos crimes, das milhares de gerações que nos antecederam.

Portanto, a especificidade humana é dupla: a do genoma e a do mundo construído pela espécie. O problema é articular essas duas especificidades. Na maioria das outras espécies animais, a articulação entre o potencial genético e as exigências do meio de vida realiza-se de forma rápida, sem exigir muitas aprendizagens. Em algumas espécies, em particular no chimpanzé, o tempo de aprendizagem necessário é maior e, portanto, a infância é mais longa. 
A espécie humana é caracterizada por um tempo de infância e de aprendizagem muito maior que o das demais espécies. Isso é um efeito da evolução. A espécie humana construiu-se e produziu seu mundo por um distanciamento cada vez maior com o seu meio natural inicial: ela deixou a floresta, ela usou ferramentas cada vez mais artificiais, ela saiu da África e conseguiu viver em condições geográficas e climáticas completamente diferentes daquelas da floresta tropical, graças à linguagem ela criou um outro tipo de mundo, simbólico etc. Ao longo dessa história, o equipamento genético dos homens tornou-se mais plástico (epigenético) e seu meio de vida (seu mundo) passou a ser mais complexo. Sendo assim, a relação do ser humano com o mundo que ele habita já não é imediata, ela requer múltiplas mediações, que têm que ser aprendidas.

São mediações instrumentais, necessárias para usar tecnicamente os objetos do mundo, e mediações sociais, que possibilitam a regulação dos desejos. A educação é o processo que permite construir essas várias mediações e, portanto, ela é o processo que articula as duas formas objetivas da especificidade humana: um genoma e um mundo historicamente produzido pelas espécies humanas. A evolução hominizou o homem como genoma específico, a cultura humanizou espaços do planeta como mundos especificamente humanos, a educação humaniza os novos membros dessa espécie para que eles possam habitar esses mundos.

O momento atual da espécie humana parece ser o de um novo salto qualitativo: as bases naturais de nosso mundo são ameaçadas (e ameaçadas por nós); somos capazes de manipular até nosso genoma; as ferramentas e a linguagem assumem formas radicalmente novas, que requerem mediações ainda mais complexas. Em compensação, muitas pessoas desejam reencontrar relações mais imediatas com o mundo, relações essas que chamamos de naturais, e que nos parecem mais autênticas. Estamos, aqui, no âmago da questão ambiental.

Nessa situação contemporânea, existem, atualmente, três opções a serem refletidas para decidir a posição que vamos assumir nos debates sobre o futuro, em particular o futuro ecológico (CHARLOT, 2019, 2020).

A primeira opção é a de um suicídio ao mesmo tempo alegre e arrogante: a opção transhumanista, ou pós-humanista, considera que o tempo da espécie humana acabou e que esta será substituída por seres biotécnicos, técnicos, eletrônicos - humanos aumentados, cyborgs, robôs etc. Essa opção apoia-se nas NBIC (nanotecnologias, biotecnologias, inteligência artificial, comunicação). Já se podem ver coisas esdrúxulas: implantação de chip em braço para abrir a porta de longe; transplantação da cabeça de um macaco no corpo de outro (que sobreviveu por 36 horas), e houve a mesma tentativa com seres humanos, em 2017. Uma grande ambição é conseguir colocar e armazenar o conteúdo do nosso cérebro em um chip, o que permitiria, notadamente, nos levar para outro lugar do universo antes que o Sol exploda. Tratase, também, de acabar com a dor, com a velhice, e, talvez, com a própria morte.

Essas ideias trazem discussões filosoficamente interessantes. Por exemplo: vale a pena ser imortal? Primeira reação: $a h$, sim! Depois, temos que refletir, porque tem gente que pensa que vai ser muito chato ser imortal. A psicanálise explica que a vida só tem sentido porque vamos morrer um dia; senão, não haveria sentido. Aliás, se formos imortais, em breve não vai mais ter lugar para novos humanos, uma vez que já somos quase oito bilhões na Terra. Um mundo sem crianças e só com idosos (300, 500, 1000 anos e mais...), é esse o nosso sonho? O que acontecerá com o atual ser humano nesse mundo pós-humano, se ele se recusar a ser aumentado? Ele tornar-se-á escravo dos novos seres dominantes, explicam os pós-humanistas. E a educação? Como disse Istvan, em vez de pagar a universidade ou de gastar horas a estudar para saber tocar Mozart no piano, bastará comprar chips, a serem implantados na nossa cabeça. É lógico: em um mundo em que seres biotecnológicos imortais são fabricados, a própria ideia de educação não faz mais sentido. E o meio de vida será tão diferente que não sei se a noção de meio ambiente ainda terá um significado. 
Por um tempo, esses devaneios foram tratados como um jogo divertido de imaginação, mas o problema é que hoje em dia existe um movimento internacional que leva muito a sério essas ideias, e as torna projetos. Assim, Ray Kurzweil, que anunciou para 2040 o momento em que a inteligência artificial tomará o poder sobre o planeta (a chamada Singularidade) tornouse diretor da engenharia na Google - e conselheiro do exército norte-americano.

A segunda opção considera a si mesmo como pós-humanismo filosófico e é uma opção que prega a modéstia. Ela inspira-se, muitas vezes, em Sloterdijk (seguidor herético de Heidegger) e desenvolveu-se, em particular, na América Latina, onde ela encontrou o apoio de tradições culturais andinas. Ela sustenta a ideia de que o ser humano tem que desistir de ocupar o lugar central no planeta. Ele só deve ser uma espécie entre outras, conectada com outras espécies vivas e com os novos seres e dispositivos tecnológicos. Nessa perspectiva, que inclui, evidentemente, uma preocupação ecológica, o mundo passa a ser uma grande rede e, nessa conectividade generalizada, o ser humano é só um entre múltiplos seres naturais e tecnológicos.

Essa opção é ecologicamente simpática, mas completamente fora da realidade da evolução e do vivo. Nunca, alguma espécie viva desistiu de ser o centro do mundo. O rato vive como sendo o centro do mundo; o mosquito comporta-se como se fosse o centro do mundo; não vejo por que, de repente, o ser humano vai desistir de ser o centro do mundo. Isso seria uma coisa estranha, que iria provar que... ele, precisamente, não é uma espécie como as outras. Além disso, acho que é fácil demais estragar o planeta por aproximadamente dez mil anos e, depois, esgueirar-se, com nova modéstia, pretendendo ser apenas uma espécie entre outras.

Eu defendo uma terceira opção: assumir esse mundo que fizemos, reconhecer nossa responsabilidade histórica e mudar profundamente nossa forma de tratar o planeta, as outras espécies vivas e a nossa própria espécie. Acho fascinante a história do ser humano, essa aventura não programada e irrepetível que criou esse ser admirável e monstruoso que é o homem. Portanto, defendo a opção de continuar essa aventura e de assumir esse mundo como sendo a nossa herança bendita e maldita. Até agora, tratamos o mundo como se fosse um simples cenário de nossa atividade, exterior a nós. Hoje em dia, devemos entender que esse mundo é a forma objetivada, sedimentada da vida e da ação das milhares de gerações humanas que nos antecederam, mesmo antes da aparição de Sapiens. O mundo somos nós, e se nós o deixamos afundar, nossa espécie afundará com ele.

Obviamente, a educação tem que desempenhar um papel muito importante na definição dessa nova relação com o planeta, com o mundo humano, com as demais espécies, com os outros seres humanos e, portanto, também, na relação de cada um de nós consigo mesmo. Evidentemente, essa nova relação antropológica com o mundo requer uma educação ambiental. Somos herdeiros do mundo e precisamos saber qual mundo queremos deixar às próximas gerações. Não se trata apenas, insisto, de respeitar o planeta e as outras espécies, mas de decidir o futuro da aventura humana. Por isso, a educação ambiental tem que ser pensada em um projeto antropológico mais amplo, além de bricolagens simpáticas, mas um tanto irrisórias quando se considera a magnitude dos problemas a serem enfrentados hoje em dia.

Esse projeto antropo-pedagógico e ecolo-pedagógico deve recusar, de forma clara, explícita e prática, as lógicas de concorrência que regem a sociedade atual - e, deste ponto de vista, ele tem uma inegável dimensão social. Fazer a opção de continuar sob novas formas a aventura humana implica apostar na solidariedade como valor central: solidariedade com o planeta, com outras espécies, com outros seres humanos. Implica, também, repelir essa pedagogia que Paulo Freire chamava de bancária, e optar pelo que considero ser a equação pedagógica fundamental: Aprender $=$ Atividade intelectual + Sentido + Prazer.

Introduzir uma pitada de educação ambiental numa escola com uma pedagogia bancária e concorrencial não passa de uma bricolagem sem grande consequência. Se quisermos uma educação ambiental, temos que redefinir as bases antropológicas da educação e das práticas de 
vida e de ensino. Desse ponto de vista, não se trata de pensar uma educação ambiental, mas a componente ambiental de um projeto antropo-pedagógico contemporâneo.

\section{Referências}

CHARLOT, B. A Mistificação pedagógica. São Paulo: Cortez, 2013.

CHARLOT, B. A questão antropológica na Educação quando o tempo da barbárie está de volta. Educar em Revista, Curitiba, v. 35, n. 73, p. 161-180, Jan./Fev. 2019. Disponível em: $<$ https://www.scielo.br/scielo.php?script=sci_arttext\&pid=S0104-

$40602019000100161 \& \operatorname{lng}=$ pt\&nrm=iso\&tlng=pt $>$. Acesso em: 13 mai. 2020.

CHARLOT, B. Éducation ou barbarie. Pour une anthropo-pédagogie contemporaine. Paris: Economica/Anthropos, 2020. 